\title{
From Fear to Love in Gay and Lesbian Near-Death Experiences and the Coming Out Process
}

\author{
Liz Dale, Ph.D \\ San Pablo, CA
}

ABSTRACT: This article illustrates the changes in thought and feeling states within gay, lesbian, bisexual, and transgender near-death experiences, and the implications for the coming out process for gay, lesbian, bisexual, and transgendered experiencers.

KEY WORDS: near-death experience; gay/lesbian/bisexual/transgender; spirituality; changes in thoughts and feelings; coming out.

In Crossing Over and Coming Home, I published a number of accounts of near-death experiences (NDEs) from within the gay/ lesbian/bisexual/transgender community (Dale, 2001). In a recent article on the experience of light on gay/lesbian/bisexual/transgender NDEs (Dale, 2006), I illustrated the concept of divine light through references to various gay/lesbian/bisexual/transgender stories from that book, along with supportive material from various authors and scholars. I also used some of the descriptive statistics that I gathered from research questionnaires and personal NDE accounts.

In this paper, I will show how various thoughts and feeling states, both positive and negative, play an important role in gay/lesbian/ bisexual/transgender NDEs, and their implications for the coming out process. Of interest is how an otherworldly event such as an NDE or out-of-body experience (OBE) can cause profound realizations and transformations for the experiencer.

Liz Dale, $\mathrm{Ph} . \mathrm{D}$., is a clinical psychologist in private practice. Reprint requests should be addressed to Dr. Dale by e-mail at lizsanpablo@aol.com. 
Before going into specific examples from the book, I would like to examine briefly the life changes within a near-death experiencer. In my particular study, 94 percent of the respondents reported that their NDE affected life in a positive way. And yet both published and unpublished accounts contain numerous examples of such negative emotional states as turbulence, fear, apprehension, depression, frustration, and powerlessness.

In reviewing these stories for thought processes, I analyzed capacity for thinking, meditation, concept formation, and ability to reflect, to conceive ideas, to concentrate, and to use imagination. In reviewing feeling states, I analyzed subjective reactions, experiences of sensing, and experiences perceived through the senses and awareness (Dale, 2001, pp. xviii-xxi).

The stories related experiences that pointed out a simple yet profound concept: in order for life changes to come about, we need to change the way we think and feel. We can see such life-altering stories in the individual accounts of gay/lesbian/bisexual/transgender NDEs. Over and over again, these NDErs faced major obstacles before change occurred. For example, one experiencer described an NDE that occurred while he was an inpatient in a major medical center in San Francisco. Just days after a shoulder surgery to remove an infected prosthesis, he desperately tried to distract himself while a nurse attempted to insert a catheter into his arm. She made three attempts before she was able to insert the catheter correctly. Suddenly, on the following day, while still in the hospital, he reported:

My mind began racing. My heart rate accelerated. I began to sweat and then to feel chilly. My blood pressure fluctuated. I began to see flashes of various periods in my life. I began to hear sounds and smell old aromas. The flashes of past experiences continued and became more vivid. Now I was actually experiencing scenes from earlier life not just the sight of them but the sounds, the smells, the tactile impressions, the heat and the cold, and even the emotions that were associated with each one. I thought to myself, "I must be dying," and wondered exactly how I should face my own death. (Dale, 2001, p. 69)

It is important to go over each of these detailed accounts to see the shifting of thoughts and feelings. In the midst of this medical emergency, this individual experienced such a shift:

At first, I felt anger at the hospital ... and I thought of calling my friend Robert ... and make sure he sued the hospital, so that at least some heirs would get some money out of this thing. But this thought 
of vengeance quickly dissolved as the barrage of sense impressions ... continued to cascade through my brain. (Dale, 2001, p. 70)

In the following series of events, some related to the immediate external environment (the nurse and intravenous line) and some to do with visions and sensory perceptions, this experiencer came to an amazing realization:

I thought that if I were really to die, I needed to call [Edel] to tell him how much I cared about him. I needed to leave this life with words of love on my lips and in my ear.... This is what it all narrows down to when everything else is stripped away. And what was that tiny strand, which was all that was left when the sensations and emotions have all been purged through my brain? It was love or God or compassion. That night, I called it love. (Dale, 2001, p. 71)

We rarely realize just what importance lies in our everyday activities, but often get caught up in the simple complacencies of life that actually have deep meanings, if only we would listen. As Paul Ferrini put it:

Love takes no hostages. It makes no bargains. It is not compromised by fear. Indeed, where love is present, fear with all its myriad conditions cannot be. $(1994$, p. 52$)$

Another NDEr addressed the negative emotions he felt when he was told during his experience that he would have to return to his physical body:

I remember feeling angry and fearful about going back - after being in all of this light - to have to go back to the darkness. And then I felt the presence of Jesus Christ all around me. The feeling of love was completely overwhelming. I felt as though I was swimming in an ocean of ecstasy. And I asked him, "Do I really have to go back?" And his answer was that I was part of God's divine plan, as is every person, and that my ultimate purpose is to love and serve God and all sentient beings. And I could tell that he understood all of my fear and doubt. (Dale, 2001, p. 102)

Again, Ferrini explained:

... the experience of real love ends your experience of the conditional world. When you experience It, you no longer feel separate from others. You lose every aspect of identity that pushes others away. You open up to a larger reality that you create with others through mutual trust.... The only way your ego knows to end the dream is to die.... What dies is not you. What dies is everything that you thought you were. Every judgement you ever made about yourself or anyone else. 
That is what dies. And what is born again is full of light and clarity. (2003, p. 53)

I experienced this kind of shift in my own NDE at age 19, when I was stung by a bee and was going into anaphylactic shock:

\begin{abstract}
Although my boyfriend had never been to my rented room, suddenly he arrived and lifted me out of the tub. He threw a towel over me and carried me to the university emergency room directly behind the campus housing. I was incredibly frightened, fighting for my life. I began to realize that my breathing was also being affected. I had no idea what anyone was doing as far as my treatment. Nor did I hear anyone talking to me. I did feel this incredible fear that I was about to die. I began to realize, despite the most intense attempts at breathing, I was not getting air into my lungs. I was in a state of total panic.... Some kind of relief flooded over me when $I$ heard a voice say, "You are dead! It's OK!" Instantly, I was transported to a new place, leaving my body behind on the ER table.... It took me many years to fully process this event. I did not share my experience with anyone for fear they would think I was strange. I guess I felt this otherworldly experience was a one-of-a-kind event.... Over the years, I have been more and more impressed at my total lack of fear of death.... I realize that someone or something (I call God or Goddess) has a special understanding of each of us, and has plans for each of us that we need to carry out to be fully realized. (Dale, 2001, pp. 18-20)
\end{abstract}

John McNeill, an ordained priest and psychotherapist, wrote a book specifically addressing "spiritual liberation for gays, lesbians and their lovers, families and friends." In the epilogue, he wrote:

In the "Rules for the Discernment of Spirits," of his Spiritual Exercises, Ignatius Loyola claimed that God is in continuous personal dialogue with those who are seeking the divine presence and that God speaks to us principally not through our minds, but through our feelings. (1996, pp. 200-201)

The Dalai Lama addressed the issue of what he referred to as "problematic emotions" in asking:

Is it possible to get rid of problematic emotions completely, or is it possible only to suppress them? According to a basic Buddhist insight, the mind is essentially luminous and knowing. Therefore, emotional problems do not reside in the mind's essence; such counterproductive attitudes are temporary and superficial and can be removed. (2005, p. 15)

He went on to discuss the numerous ways feeling states can be altered along with ways to ensure compassion. As far as altering the mind, he wisely reminded us: 
We cannot feel desire and hatred at exactly the same time towards the very same object ... which shows these two attitudes function in contradiction to each other. When one of them increases in strength, the other decreases. $(2005$, p. 21)

The next dilemma is: What can be done to reformulate our thoughts? The Dalai Lama went on to write:

Valid cognition supports love and compassion. Their production needs no assistance from the ignorance that misconceives objects as existing inherently or in and of themselves. (2005, pp. 21-22)

He summarized this theme as follows:

The cultivation of love requires understanding that all beings want happiness, and all beings are beset by suffering.... Our minds and bodies do not operate completely under our own control but under the influence of karma (tendencies created by previous actions) and emotions.... In ordinary life we are born from and into the pervasive influence of karma and afflictive emotions. Even when we do not think we are feeling anything, we are under the influence of causes and conditions beyond our control - stuck in a cycle that is prone to suffering. When you realize how this cycle makes you susceptible to all sorts of unwanted events, you want to get rid of it as much as you would want to remove a speck of dust from your eye. (2005, pp. 87-89)

I would like to conclude this section of the paper with Ferrini's summary of the meaningful analysis of one's thoughts and feelings:

Can you imagine a world in which each person understood that his only responsibility was to give and receive love? That world, my friend, is at your fingertips. Whenever there is lack in your life, there is need to bring love. Whenever you think you are not getting enough, there is some aspect of love and support you are withholding from another. Don't withhold your love and support. Give it freely that you may receive abundance of love that is your birthright. (2003, pp. 130 131)

\section{The Coming Out Process}

An important concept noted in many of the gay/lesbian/bisexual/ transgendered NDE narratives is the concept of coming out. Before I present examples to illustrate the coming out process, we need to define coming out. McNeil (1996) wrote about coming out and the issue of accepting gayness. He spent much of his life working with gay and lesbian people within his ministry and psychotherapy practice. Over 
the years, he has also led various workshops and retreats for gay and lesbian people. He has also reflected on "my own lifelong struggle to accept my gayness with gratitude as a gift from God" (McNeil, 1996, p. xii). McNeil offered the following definition of coming out:

Most gays and lesbians become consciously aware of their sexual orientation during puberty.... Once one has become aware of samesex feelings, a period of time usually elapses before one is able to label them as such....

The process of coming out - telling others than one is lesbian or gay - is identical with the process of self-acceptance. $(1996$, p. 68$)$

"Coming out of the closet," as it is sometimes referred to, is an important way many gay/lesbian/bisexual/transgendered persons address the issue of self-acceptance. Historically, many books and articles directly addressed the gay/lesbian/bisexual/transgendered and societal processes, stereotypes as well as the self-hatred that comes with internalized homophobia. Self-acceptance becomes a lifelong challenge with numerous painful stumbling blocks along the way. Many gay/lesbian/bisexual/transgendered people would be more than pleased to live within a culture of openness, living to their full potential without fear of societal rejection.

Worldwide, many gay/lesbian/bisexual/transgendered people cannot openly live their truth. Byrne Fone clarified that "Homophobia is the last acceptable prejudice in an age when racial and ethnic bigotry are viewed with distaste" (2000, back cover). Fone listed a number of derogatory and stereotypical slurs that gay/lesbian/bisexual/transgendered people might be called, not confined to any specific locale or culture, including "vermin," "perverts," "inferior," "cowards," "unconstrained," "socially worthless," and "dangerous" (2000, p. 406). Over many years, then, gay/lesbian/bisexual/transgendered individuals face societal alienation within the various cultures here in America and throughout the world. Fone revealed a historical backdrop to coming out versus staying in the closet:

During the 1960s, when 82 percent of American men and 58 percent of the women surveyed believed that only Communists and atheists were more dangerous than homosexuals, many homosexuals felt that the closet was the safest place to be. $(2000$, p. 406$)$

Homophobia is commonplace in American culture and throughout the world. In America, many people have been at least as unaccepting of bisexual and transgendered people as they have been for gay and lesbian individuals. Even within the gay/lesbian/bisexual/transgen- 
dered community itself, there are various factions and divisiveness that take away the possibility of cohesion. It is not surprising, then, given all of this background, that coming out is seen as one of the more challenging issues and one of the prominent themes in gay/lesbian/ bisexual/transgendered NDEs.

My review of the accounts of the gay/lesbian/bisexual/transgendered NDEs and NDE-like experiences revealed many fascinating accounts of the coming out process. Amazingly, it was through NDEs and NDElike experiences that overt self-doubt and the self-loathing of internalized homophobia dissipated for many of these experiencers, allowing self-acceptance to surface and societal fears to subside. In place of negative emotions and various distorted perceptions among these NDErs, divinely inspired accounts of self-acceptance were realized. One experiencer related the following account:

Once again we began to review my life.... I could see all the self-doubt that I had in my life centered around the question of my being of worth to God being that I was a gay man. It was then that I mustered up the courage to ask these beings something I could sense they were waiting for me to ask. I asked, "Is it $O K$ to be gay?" and they laughed and said, "Who do you think made gay people?" ... I felt like I fit in for the first time in my entire life ... completely fit it. (Dale, 2001, pp. 35-36)

Another gay/lesbian/bisexual/transgendered NDEr reported having had two NDEs five years apart. The second NDE followed an ingestion of numerous sleeping pills and alcohol after the experiencer was told of a friend's unexpected death. During the ensuing NDE, his recently decreased friend Richard appeared to him:

Richard's spirit seemed all-pervasive and completely powerful.... Our communication was telepathic and overlapping.... Richard seemed acutely aware of my estrangement from my family and friends as well as my self-loathing and self destruction - which came largely from my negative feelings about my sexuality and sensitivity. He indicated most emphatically that I should openly celebrate and honor my sexuality as a precious gift from God. This was a startling revelation for me especially after a lifetime of secrecy, fear and guilt. (Dale, 2001, pp. 110-113)

\section{Conclusion}

The purpose of this article is to illustrate shifts from fear and anger to love and understanding in gay/lesbian/bisexual/transgendered 
NDEs and their impact on the concept and complex nature of the coming out process. Historically, most societies tend to look less than favorably on the gay/lesbian/bisexual/transgendered population. Over the years and up to the present time, people who do not fit into the norms that have been set up by our society are typically either ignored, ridiculed, mistreated, or physically endangered. It is really not surprising that many people in the gay/lesbian/bisexual/transgendered communities prefer to remain as invisible as is humanly possible. As noted above, homophobia or heterosexism is not confined to America alone. Relevant to this topic, Keep Not Silent, a recent film by Ilil Alexander (2004) that won the Israeli Oscar for Best Documentary followed the lives of three women who identified as lesbians. Each of these women explained the reasons they had not been able to come to terms with their Jewish orthodox community and their own sexuality. In the words of Shai Ginsburg, who reviewed this powerful film:

All three of Alexander's women remain unable to openly realize their sexuality without fear of devastating communal sanctions.... The hetero-normative parameters of ultra-orthodox life remains in force. (2006, p. 76)

In this paper, I shared the NDEs and NDE-like experiences of anonymous gay/lesbian/bisexual/transgendered people. Each of these individuals found the otherworldly experience one in which he or she felt fully accepted and loved. Over and over, they described a loving, powerful, accepting divinity that is open to accepting the gay/lesbian/ bisexual/transgendered experience. It should not surprise anyone reading these accounts that, after returning to "normal" life, or, rather, life after the NDE, experiencers finds reintegration rather challenging. And it should not be surprising that a number of experiencers fall into states of sadness and depression while the experience is being absorbed. My hope in publishing this material is that some individuals will benefit from a deeper understanding of the gay/lesbian/bisexual/transgendered NDE and the coming out process. It is essential that more research be conducted into the NDE and the gay/lesbian/bisexual/transgendered community and that this powerful material be shared with interested audiences in all cultures throughout the world. As the NDE community has come to realize experientially, so much can be learned from reading and sharing these near-death accounts. 


\section{References}

Alexander, I. (Dir.). (2004). Keep not silent: Ortho-dykes [Film]. New York, NY: Women Make Movies.

Dalai Lama. (2005). How to expand love. New York, NY: Atria Books.

Dale, L. (2001). Crossing over and coming home: Twenty-one authors discuss the gay near-death experience as a spiritual transformation. Houston, TX: Emerald Ink.

Dale, L. (2006). Experiences of light in gay and lesbian near-death experiences. Journal of Near-Death Studies, 24, 175-178.

Ferrini, P. (2003). Love without conditions. Greenfield, MA: Hearways Press.

Fone, B. (2000). Homophobia: A history. New York, NY: Henry Holt/Metropolitan Books.

Ginsburg, S. (2006). Orthodykes. Tikkun, 21, 75-76.

McNeil, J. J. (1996). Taking a chance on God: Liberating theology for gays, lesbians, and their lovers, families, and friends. Boston, MA: Beacon Press. 